\title{
In Situ Characterization at Elevated Temperatures of a New Ni-Based Superalloy VDM-780 Premium
}

\author{
C. SOLÍS, J. MUNKE, M. BERGNER, A. KRIELE, M.J. MÜHLBAUER, \\ D.V. CHEPTIAKOV, B. GEHRMANN, J. RÖSLER, and R. GILLES
}

\begin{abstract}
A new Ni-base superalloy VDM-780 Premium was developed for higher service temperatures (above $650{ }^{\circ} \mathrm{C}$ ), keeping the good processing characteristics of alloy 718 . This article presents, for the first time, the morphology and the microstructure characterization of this newly developed superalloy VDM-780 by means of scanning electron microscopy (SEM) and neutron and X-ray diffraction (XRD), after three different aging treatments performed for setting up different microstructures. Results show the presence of the $\gamma$-matrix, $\gamma^{\prime}$-hardening phase, and a high-temperature phase whose structure is compatible with $\delta$ and $\eta$ phases but whose exact crystal structure or the possibility of two different high-temperature phases still remains open. Rietveld refinements have allowed phase identification, determination of the lattice constants, and the weight fractions of constituting phases and shown that the presence of the different phases, amount, and morphology highly depend on the aging treatments. No traces of the $\gamma^{\prime \prime}$ phase are observed regardless of the heat treatment. In situ neutron diffraction (ND) studies at high temperature have allowed the determination of the solvus temperatures of the different phases present in each material after the corresponding aging treatment as well as the study of the evolution of their lattice parameters with temperature. The Vickers hardness (HV) of the three different samples was measured, and the results are correlated with the amount and particle size of the $\gamma^{\prime}$-hardening phase of each sample.
\end{abstract}

https://doi.org/10.1007/s11661-018-4761-6

(C) The Author(s) 2018

\section{INTRODUCTION}

Ni-BASED superalloys are widely used for high-temperature applications, as parts for jet engines, due to their good mechanical properties at high temperatures together with their resistance to degradation in corrosive or oxidizing conditions. ${ }^{[1,2]}$ Among these, Alloy 718 is the most widely used Ni-based superalloy, due to its unique mechanical properties and good processing characteristics. $^{[3]}$

C. SOLÍS, J. MUNKE, and R. GILLES are with the Heinz MaierLeibnitz Zentrum (MLZ), TU München, Lichtenbergstr. 1, 85748 Garching, Germany. Contact email: cecilia.solis@frm2.tum.de M. BERGNER and J. RÖSLER are with the Institut für Werkstoffe, Technische Universität Braunschweig, 38106 Braunschweig, Germany. A. KRIELE is with the Helmholtz Zentrum Geesthacht, Max-PlanckStraße 1, 21502 Geesthacht, Germany. M.J. MÜHLBAUER is with the Heinz Maier-Leibnitz Zentrum (MLZ), TU München and also with the Institute for Applied Materials (IAM), Karlsruhe Institute of Technology (KIT), Hermann-von-Helmholtz-Platz 1, 76344 Eggenstein-Leopoldshafen, Germany. D.V. CHEPTIAKOV is with the Laboratory for Neutron Scattering and Imaging, Paul Scherrer Institut (PSI), 5232 Villigen, Switzerland. B. GEHRMANN is with the VDM Metals International GmbH, Kleffstraße 23, 58762 Altena, Germany.

Manuscript submitted March 15, 2018.

Article published online July 9, 2018
In the 718-type Ni-based superalloys, the austenitic matrix ( $\gamma$ phase) is strengthened by intermetallic precipitates of $\mathrm{Ni}_{3} \mathrm{Al}\left(\gamma^{\prime}, \mathrm{fcc} \mathrm{L}_{2}\right.$ structure $)$ and $\mathrm{Ni}_{3} \mathrm{Nb}\left(\gamma^{\prime \prime}\right.$, bct $\mathrm{DO}_{22}$ structure), and the existence of coprecipitates of both phases with different morphologies (plate, needle, cube, or disc shape) was also observed. ${ }^{[4,5]}$ Other phases that can also be formed are $\mathrm{Ni}_{3} \mathrm{Nb}$-based ( $\delta$, orthorhombic $\mathrm{DO}_{a}$ structure) and $\mathrm{Ni}_{3}$ Ti-based $\left(\eta\right.$, hexagonal $\mathrm{DO}_{24}$ structure). The limiting service temperature $\left(650^{\circ} \mathrm{C}\right)$ of alloy 718 is due to the instability of the $\gamma^{\prime \prime}$ phase, which transforms into $\delta$ phase, and the alloy loses its creep resistance. The existence of the different phases and the quantity, shape, and size of the different precipitates and coprecipitates depend on composition, processing conditions, and heat treatment. It is especially crucial to control the evolution of the different phases at high temperature in order to tailor the mechanical properties. ${ }^{[6-9]}$

The aim of increasing the operation temperature of the Ni-based superalloys, which allows engine manufacturers to improve fuel efficiency and, thus, results in reduced emissions, forces the development of materials stable at higher temperatures. The last few decades the scientific community has put great effort into the development of Ni-based alloys with operation temperatures above $650{ }^{\circ} \mathrm{C}$ while keeping the good processing 
characteristics of alloy 718. WASPALOY* has a high

*WASPALOY is a trademark of United Technologies Corporation, Farmington, CT.

amount of $\gamma^{\prime}$ phase, which allows its use at higher temperatures; on the other hand, the high $\gamma^{\prime}$ solvus temperature produces poor hot formability. ${ }^{[10]}$ The development of the alloy 718Plus, in which half of the $\mathrm{Fe}$ of the alloy 718 is replaced by Co, improves the performance at high temperatures and is expected to be easier to process and to weld. ${ }^{[11]}$ With improved composition, new, VDM-780 Premium (Ni, Co, Cr, $\mathrm{Nb}$, Mo, Al, Fe, and Ti) was developed for higher service temperature and its structure and performance are under investigation. ${ }^{[10,12]}$

This work presents the structural characterization of the new VDM-780 Premium after different aging conditions by means of neutron diffraction (ND) and X-ray diffraction (XRD) at room temperature (RT) and elevated temperatures. The morphology of the different phases is studied by scanning electron microscopy (SEM). Furthermore, the solvus temperature of the different phases forming this alloy, i.e., the $\gamma^{\prime}$-hardening phase and the high-temperature phase, is determined by means of in situ high-temperature ND.

\section{EXPERIMENTAL}

Three different samples of the Ni-based superalloy VDM-780 Premium, with the same composition (25 pct $\mathrm{Co}, 18$ pct $\mathrm{Cr},<3$ pct Fe, 3 pct Mo, 5.4 pct Nb, 2 pct $\mathrm{Al}, 0.2$ pet Ti wt pet, balance of $\mathrm{Ni}$ ) but after three different aging conditions, are investigated in this work. The aging conditions were performed to form diverse microstructures, i.e., age condition 1 (sample VDM-780-1) with only high-temperature phase, age condition 2 (sample VDM-780-2) with mainly $\gamma^{\prime}$-hardening phase, and age condition 3 (sample VDM-780-3) with a contribution of both $\gamma^{\prime}$-hardening precipitates and the high-temperature phase that gives rise for fine grain forgeability. The description of the aging conditions is summarized in Table I with $\mathrm{FC}=$ furnace cooling, $\mathrm{WQ}=$ water quenching, and $\mathrm{AC}=$ air cooling.

The morphology was investigated using a field emission-scanning electron microscope (FE-SEM, Zeiss LEO 1550 Gemini) with an InLens detector, and the elemental analysis was carried out with energy-dispersive X-ray spectroscopy (EDX, Helios NanoLab 650, FEI). XRD patterns were recorded in Bragg-Brentano geometry by using a PANalytical Empyrean high-resolution powder diffractometer with Mo $K_{\alpha}$ radiation source $(\lambda=0.7107 \AA)$ for deep penetration depth at the Materials Science Laboratory of Heinz Maier-Leibnitz Zentrum (MLZ).

ND measurements were performed in Debye-Scherrer geometry for phase analysis at RT at the high-resolution powder diffractometer SPODI at MLZ.$^{[13,14]}$ Neutrons with a wavelength $\lambda$ of $1.548 \AA$ from the Ge (551) monochromator were incident on the cylindrical probes of $6 \mathrm{~mm}$ in diameter and $40 \mathrm{~mm}$ in length. For minimization of the preferred orientation effect on the diffraction pattern, the sample placed into a thin-wall $(0.15 \mathrm{~mm})$ vanadium can of $7 \mathrm{~mm}$ in diameter was constantly rotated during data collection. Each sample was measured for 4 hours.

For the determination of the solvus temperature and in order to follow the evolution of the lattice parameters with temperature, in situ ND measurements at high temperature were performed on cylindrical samples of 6 $\mathrm{mm}$ in diameter and $20 \mathrm{~mm}$ in length (threaded at one end to mount on the furnace sample stick) at the SINQ spallation source of the Paul Scherrer Institute (PSI (Villigen, Switzerland)) using the high-resolution diffractometer for thermal neutrons (HRPT). ${ }^{[15]}$ Measurements were performed by using a water-cooled furnace with a tantalum foil heater tube and two radiation shields within the vacuum chamber, which can reach up to $1125^{\circ} \mathrm{C}$, and by using a wavelength $\lambda$ of $1.89 \mathrm{~A}$, a $2 \theta$ range from 10 to $160 \mathrm{deg}$, and 2 hours of measuring time for each temperature. The data evaluation of diffractograms was performed with Rietveld refinement $^{[16]}$ using the Highscore Plus software ${ }^{[17]}$ for the XRD and the Fullprof software ${ }^{[18]}$ for the ND measurements.

The different structures were extracted from Rietveld refinement, including lattice parameters and weight fractions. Where possible, the crystallite average sizes were also found by taking into account that the full-width half-maximum (FWHM) of the peaks is influenced by the size of the particles if the size is clearly below 100 or $20 \mathrm{~nm}$ when using XRD or ND, respectively, using the Scherrer equation ${ }^{[19]}$ :

$$
\beta_{\text {size }}=\frac{0.9 \lambda}{t \cos \theta}
$$

where $\beta$ is the FWHM of the diffraction peaks after correction of instrumental broadening and taking into account the profile shape; $\lambda$ is the wavelength, $\theta$ is the diffraction angle, and $t$ is the average crystallite size.

The lattice misfit, $\delta$, between the $\gamma$-matrix and the $\gamma^{\prime}$-hardening phase, which is defined as the relative

Table I. Aging Conditions Description

\begin{tabular}{llc}
\hline Age Condition 1 & Age Condition 2 & Age Condition 3 \\
\hline $1000{ }^{\circ} \mathrm{C} / 0.5 \mathrm{~h} / \mathrm{FC} 1 \mathrm{~K} / \mathrm{min}$ & $980{ }^{\circ} \mathrm{C} / 1.5 \mathrm{~h} / \mathrm{WQ}$ & $900{ }^{\circ} \mathrm{C} / 11 \mathrm{~h} / \mathrm{AC}$ \\
$975{ }^{\circ} \mathrm{C} / 16 \mathrm{~h} / \mathrm{WQ}$ & $720^{\circ} \mathrm{C} / 8 \mathrm{~h} / \mathrm{FC} 50 \mathrm{~K} / \mathrm{h}$ & $955^{\circ} \mathrm{C} / 1 \mathrm{~h} / \mathrm{FC} 4 \mathrm{~K} / \mathrm{min}$ \\
& $620^{\circ} \mathrm{C} / 8 \mathrm{~h} / \mathrm{AC}$ & $800{ }^{\circ} \mathrm{C} / 8 \mathrm{~h} / \mathrm{FC} 50 \mathrm{~K} / \mathrm{h}$ \\
& & $650{ }^{\circ} \mathrm{C} / 8 \mathrm{~h} / \mathrm{AC}$ \\
\hline
\end{tabular}


difference between the lattice parameters of the $\gamma^{\prime}$ precipitates and the $\gamma$ matrix, is also determined ${ }^{[20]}$ :

$$
\delta=\frac{a_{\gamma^{\prime}}-a_{\gamma}}{0.5\left(a_{\gamma^{\prime}}+a_{\gamma}\right)}
$$

where $a$ is the lattice parameter of the $\gamma$ and $\gamma^{\prime}$ phases, respectively.

The Vickers hardness (HV) tests were performed with a Struers DuraScan 20 Microhardness tester by using two different test forces, 29.42 N (HV3) and 98.07 N (HV10), along central lines of plate samples.

\section{RESULTS AND DISCUSSION}

The morphology of the three different samples (same composition but with the aging conditions described in Table I) can be observed in SEM images of Figure 1 (with two different magnifications). Sample VDM-780-1 shows big grains of the $\gamma$-matrix together with some plate- and needlelike precipitates of around 2- to 3- $\mu \mathrm{m}$ length and a thickness of a few hundred nanometers, assigned to the high-temperature phase. In contrast, sample VDM-780-2 shows very small precipitates (size $<20 \mathrm{~nm}$ ) related to $\gamma^{\prime}$ and just a few platelike precipitates (a bit shorter than those of sample 1) of the high-temperature phase. Sample VDM-780-3 shows precipitates of different sizes ranging from the smallest $(\sim 10 \mathrm{~nm})$ to intermediate $(20-$ to $100-\mathrm{nm}$ ) sizes that can be associated with the $\gamma^{\prime}$-hardening phase, and also a smaller amount of large platelike precipitates $\left(\sim 0.5 \times 4 \mu \mathrm{m}^{2}\right)$ similar to those observed in sample VDM-780-1 that can be assigned to the high-temperature phase.

A more detailed SEM image of a high-temperature precipitate (from sample VDM-780-3) can be observed in Figure 2(a). Figure 2(b) shows two different areas analyzed by EDX: in yellow, the area of the high-temperature phase whose EDX analysis is shown in
Figure 2(c); and in blue, the area of the matrix whose corresponding EDX analysis is shown in Figure 2(d). The big plate- and needlelike high-temperature precipitates are rich in $\mathrm{Nb}, \mathrm{Ti}$, and $\mathrm{Al}$, when comparing EDX analysis and by taking into account of the nominal composition of the alloy. This fact agrees with the expected composition of both high-temperature precipitates $\delta-\mathrm{Ni}_{3} \mathrm{Nb}(\mathrm{Ti}, \mathrm{Al})$ and $\eta-\mathrm{Ni}_{3} \mathrm{Ti}$ or $\mathrm{Ni}_{6} \mathrm{AlNb}{ }^{[21]}$

XRD patterns of the three samples (with the same composition but with different aging conditions listed in Table I) are depicted in Figure 3. Bragg reflections of the $\gamma$-matrix (ICSD-102819), $\gamma^{\prime}$-hardening phase (ICSD-58017), $\delta$ (ICSD-105176), and $\eta$ (ICSD-645124) high-temperature phases are implemented as simulation for comparison at the bottom. Patterns show Bragg reflections of the $\gamma$-matrix, $\gamma^{\prime}$-hardening phase, or high-temperature phases $\delta$ and $\eta$, but no trace of the $\gamma^{\prime \prime}$-hardening phase, as is characteristic for the alloy 718 observed after any of the studied aging conditions. It is also worth noting that the phases present in the material and their volume fractions depend on the aging condition. Thus, sample VDM-780-1 only shows $\gamma$-matrix, while sample VDM-780-2 also shows $\gamma^{\prime}$-hardening phase. Finally, the aging condition of sample VDM-780-3 gives rise not only to the $\gamma$-matrix and the $\gamma^{\prime}$-hardening phase but also shows Bragg reflections that can be ascribed to both $\eta$ and $\delta$ high-temperature phases. Note that the small peak at $2 \theta$ to $17.15 \mathrm{deg}$ and labeled with $\mathrm{Al}$ is due to the aluminum holder.

In order to analyze deeply the structure of this new alloy, ND measurements were performed because neutrons allow study of a real bulk volume (of the order of cubic centimeters) as compared to essentially the surface analysis provided by X-rays. High-resolution ND patterns measured at RT on the SPODI instrument (MLZ) of the three different samples are plotted in Figure 4. Similar to the results observed by XRD, the ND patterns of the different VDM-780 samples possess

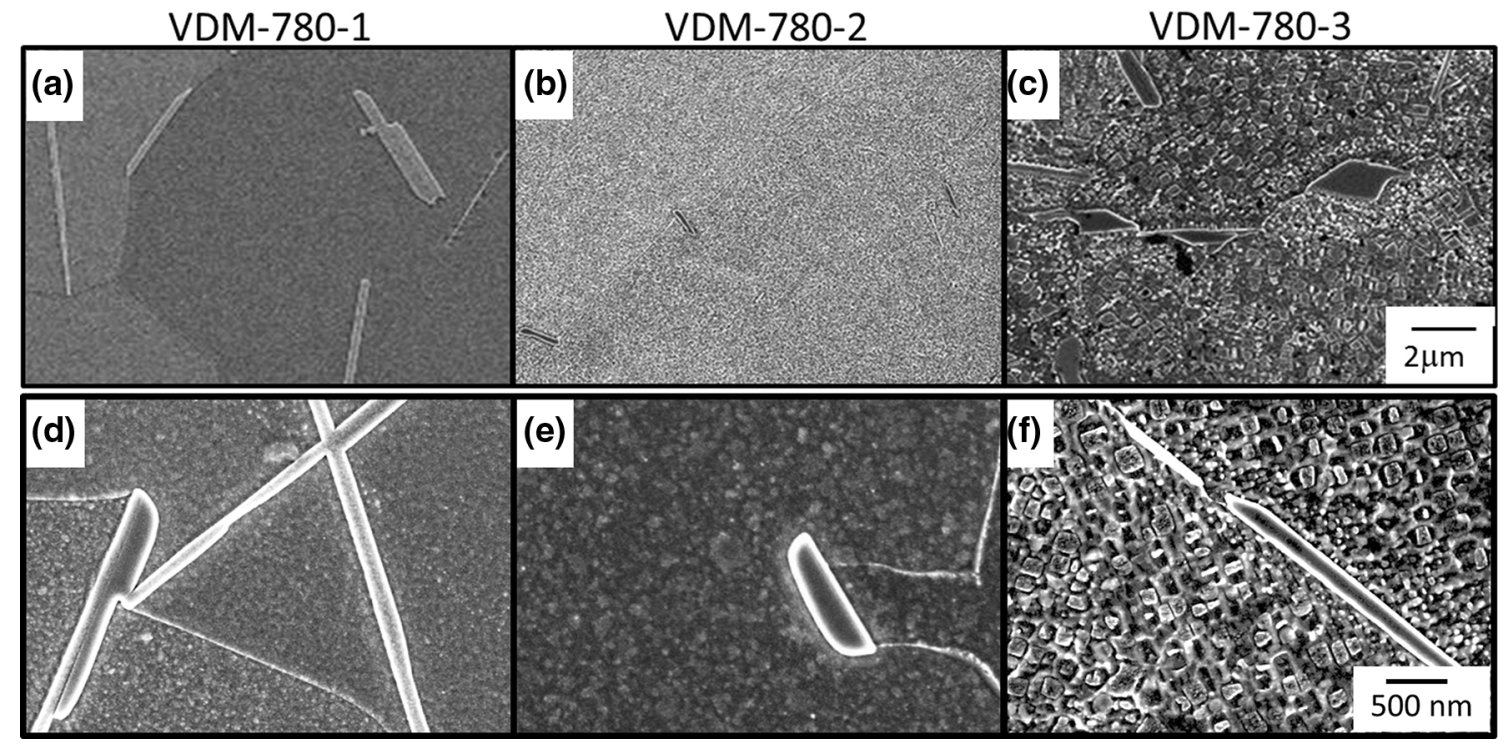

Fig. 1-SEM images of the three different samples $(a)$ VDM-780-1, $(b) 2$, and $(c) 3$ and details of the constituting phases using $(d)$, $(e)$, and $(f)$ higher magnifications. 

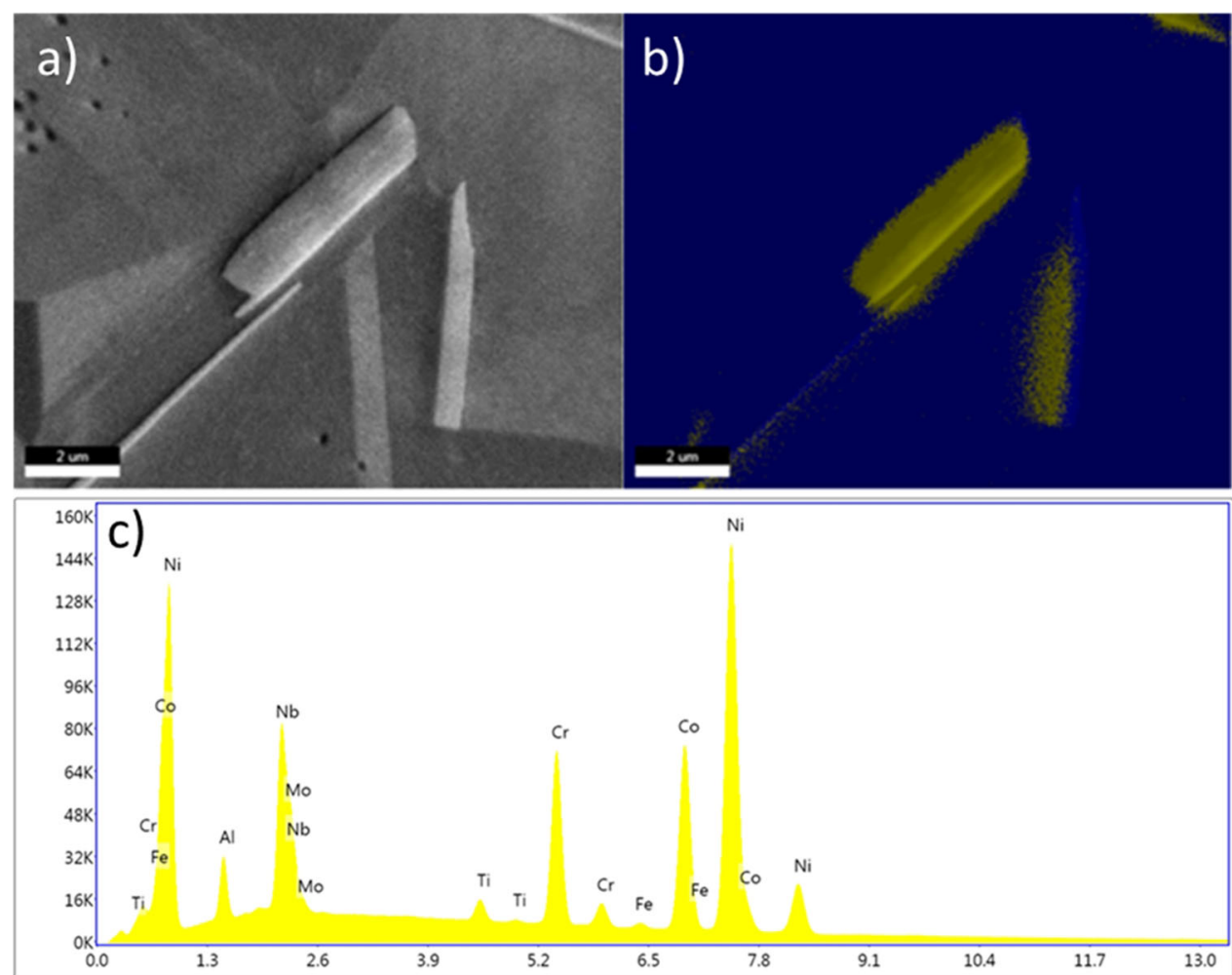

\begin{tabular}{|ccc|}
\hline Element & Weight \% & Atomic \% \\
\hline AlK & 2.28 & 5.12 \\
\hline NbL & 16.74 & 10.91 \\
\hline MoL & 2.71 & 1.71 \\
\hline TiK & 1.03 & 1.30 \\
\hline CrK & 10.23 & 11.91 \\
\hline FeK & 0.32 & 0.34 \\
\hline CoK & 19.33 & 19.86 \\
\hline NiK & 47.36 & 48.84 \\
\hline
\end{tabular}

Lsec: 505.70 Cnts 0.000 keV Det: Apollo XL-SDD Det

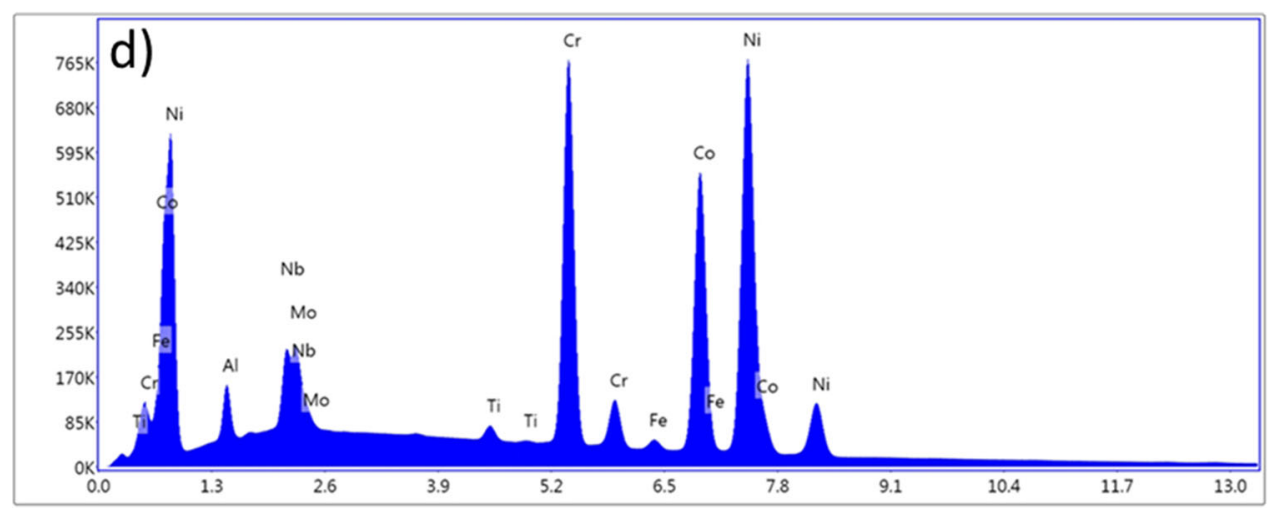

\begin{tabular}{|ccc|}
\hline Element & Weight \% & Atomic \% \\
\hline AlK & 1.70 & 3.67 \\
\hline NbL & 6.13 & 3.84 \\
\hline MoL & 3.92 & 2.38 \\
\hline TiK & 0.59 & 0.72 \\
\hline CrK & 19.44 & 21.77 \\
\hline FeK & 0.58 & 0.60 \\
\hline CoK & 25.51 & 25.21 \\
\hline NiK & 42.13 & 41.80 \\
\hline
\end{tabular}

Lsec: 3054.10 Cnts 0.000 keV Det: Apollo XL-SDD Det

Fig. 2-(a) SEM image of a high-temperature precipitate of sample VDM-780-3; $(b)$ areas used for the EDX analysis of the high-temperature precipitate (yellow) and the matrix (blue); and corresponding EDX analysis of the $(c)$ high-temperature precipitate and (d) matrix (Color figure online).

additional peaks along with the fundamental reflections of the $\gamma$-phase matrix (marked with black rhombus in Figure 4) and the presence and volume fraction of the different phases depend on the aging treatment. The additional peaks can be indexed corresponding to the $\gamma^{\prime}$-hardening phase $(\bullet$ : red solid circle), the $\delta$ high-temperature phase ( $\Delta$ : green triangle), and the $\eta$ high-temperature phase (o: empty blue circle). It is also worth noting that, also by ND, no hint of the presence of $\gamma^{\prime \prime}$ is visible regardless of the aging treatment. The ND study shows some additional phases in the three samples in comparison with XRD analysis (due to the larger measured sample volume). Thus, sample VDM-780-1 presents, together with the $\gamma$-matrix, some traces of the high-temperature phases ( $\eta$ and/or $\delta$ ), while samples
VDM-780-2 and 3 also show $\gamma^{\prime}$-hardening phase (although the amount of each phase differs for the two samples, as will be analyzed later). The obtained $\gamma$-matrix, $\gamma^{\prime}$-hardening phase, and $\delta$ high-temperature phase agree with ThermoCalc predictions obtained for the alloy Ni-18.7Cr-2.96Mo-0.20Ti-2.0Al-5.4Nb-25.0Co (which is in the compositional range of Alloy 780), but from these calculations, no $\eta$ high-temperature phase was expected for the low Ti content. ${ }^{[22]}$

From these ND patterns, it can also be observed that the most intense reflections of both $\delta$ and $\eta$ high-temperature phases are located at close positions in scattering angle, which makes it very difficult to discriminate between both high-temperature phases or to assume the presence of both. In order to easily see this fact, Figure 5 

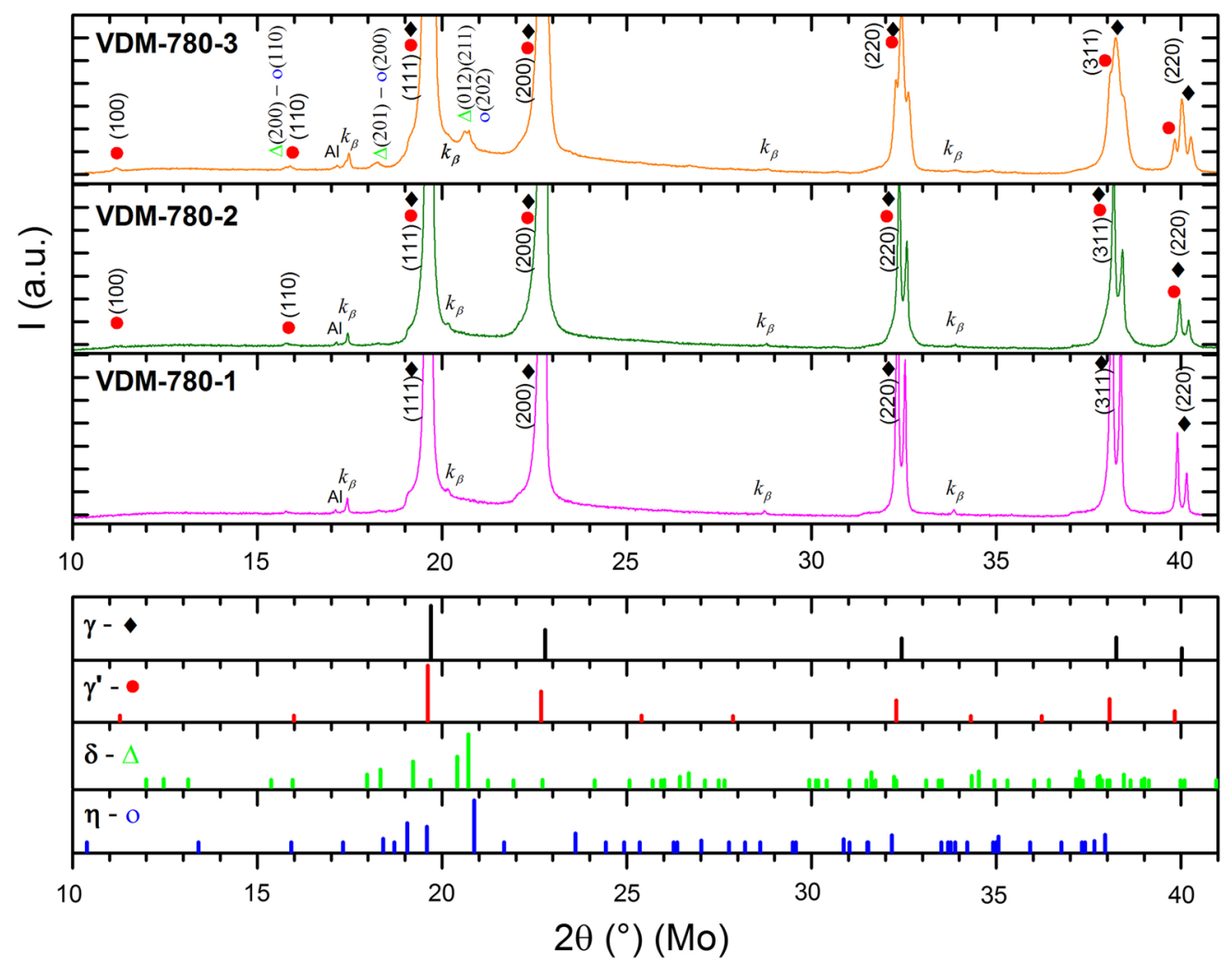

Fig. 3-XRD patterns of VDM-780 1, 2, and 3 (top) and simulations of structures of the $\gamma$-matrix, $\gamma^{\prime}$-hardening precipitates, and both $\delta$ and $\eta$ high-temperature phases (bottom).

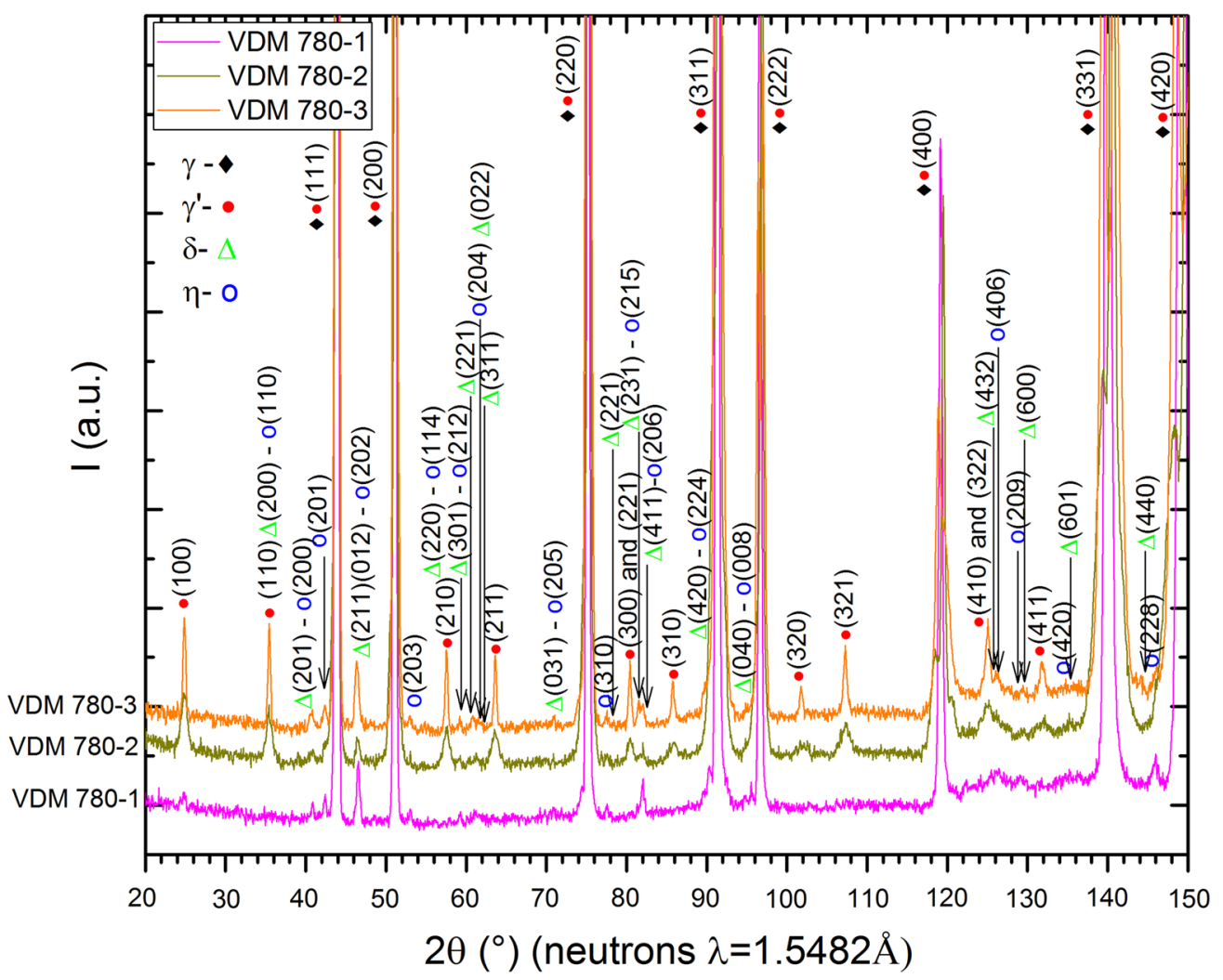

Fig. 4-ND patterns of the VDM-780-1, 2, and 3 superalloys (from SPODI) after different aging treatments with the main peaks of the different phases ( $\gamma$ : black rhombus, $\gamma^{\prime}$ : red solid circle, $\delta$ : green triangle, and $\eta$ : empty blue circle) (Color figure online). 


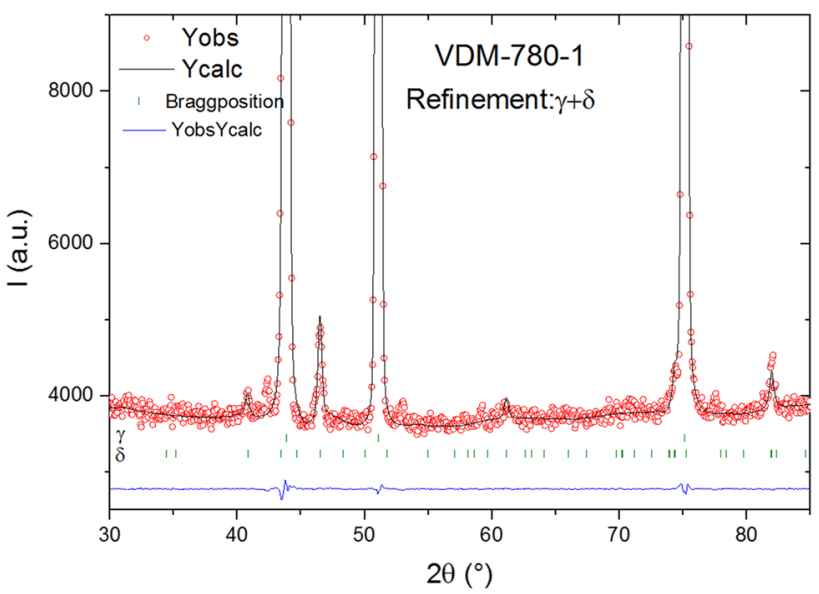

(a)

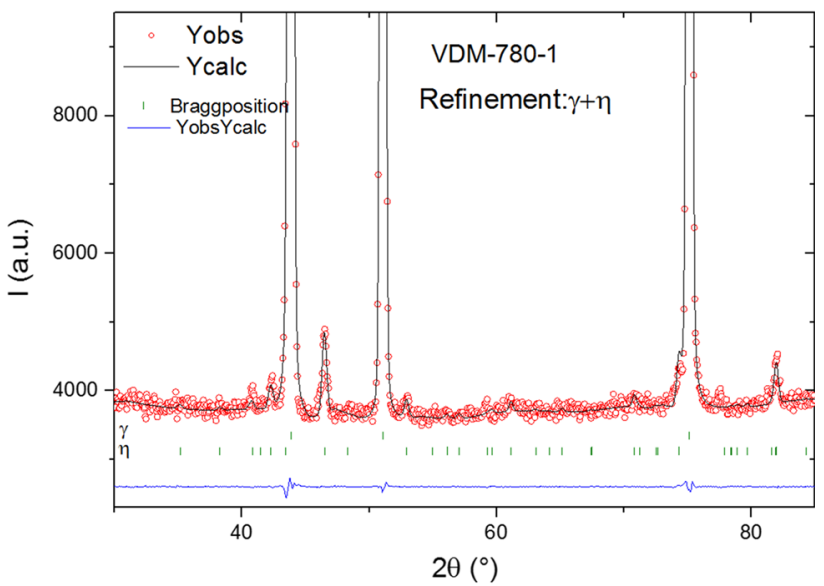

(b)

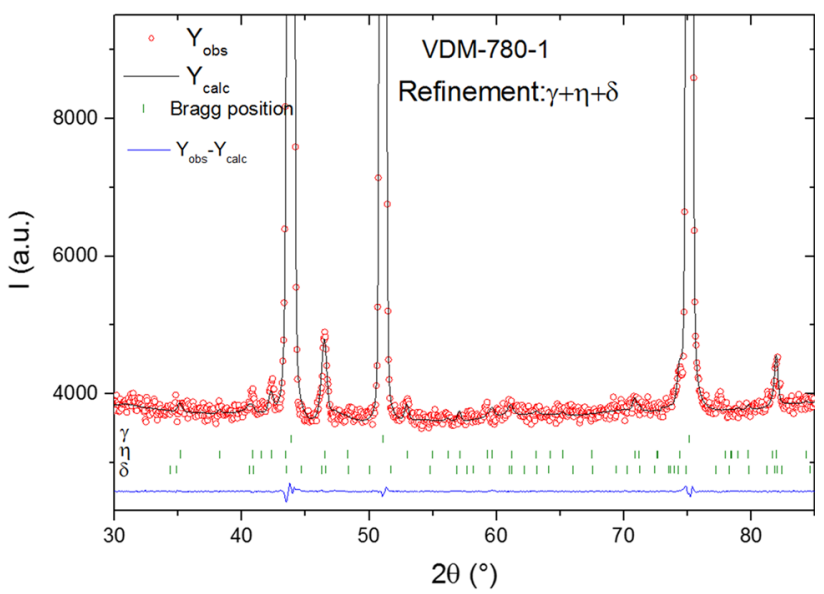

(c)

Fig. 5-Zoom of the high-resolution ND patterns of sample VDM-780-1 at RT and results of the corresponding Rietveld refinement of the full pattern by taking into account the $\gamma$-matrix and $(a)$ only the high-temperature phase $\delta, \quad(b)$ only the high-temperature phase $\eta$, and $(c)$ both high-temperature phases $\delta$ and $\eta$. The observed data (red circles), calculated data (black line), and difference plots (blue line), together with the positions of the Bragg reflections, are depicted for all phases $(\gamma, \eta$, and $\delta$ green markers) (Color figure online). shows the Rietveld refinement of sample VDM-780-1 by taking into account, together with the $\gamma$-matrix, only the high-temperature $\delta$ phase (a), only the high-temperature

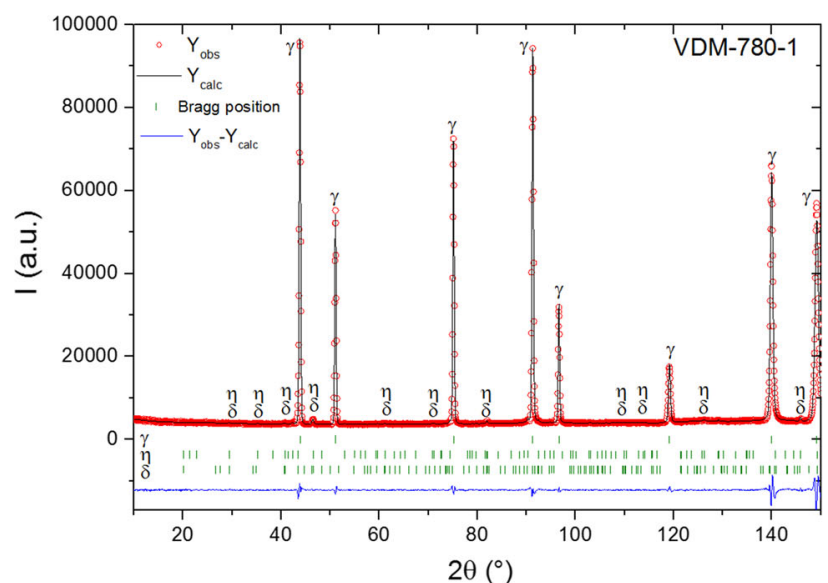

(a)

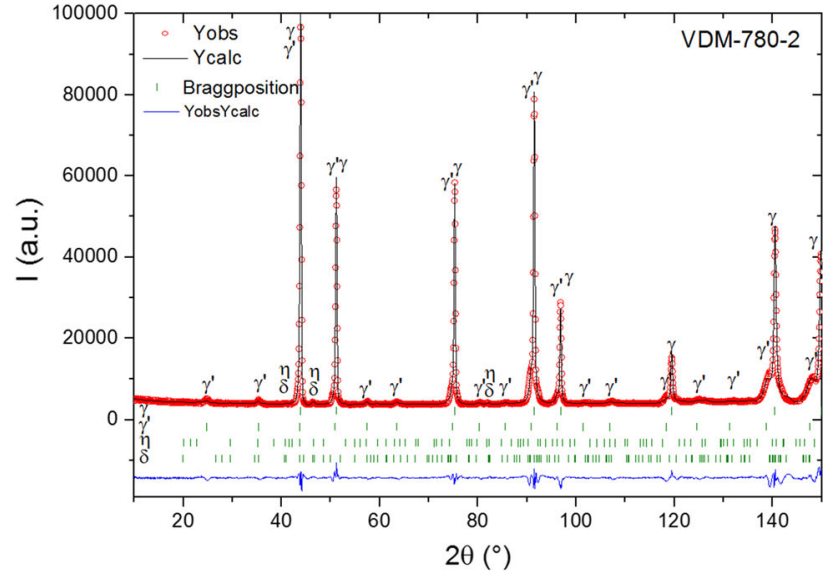

(b)

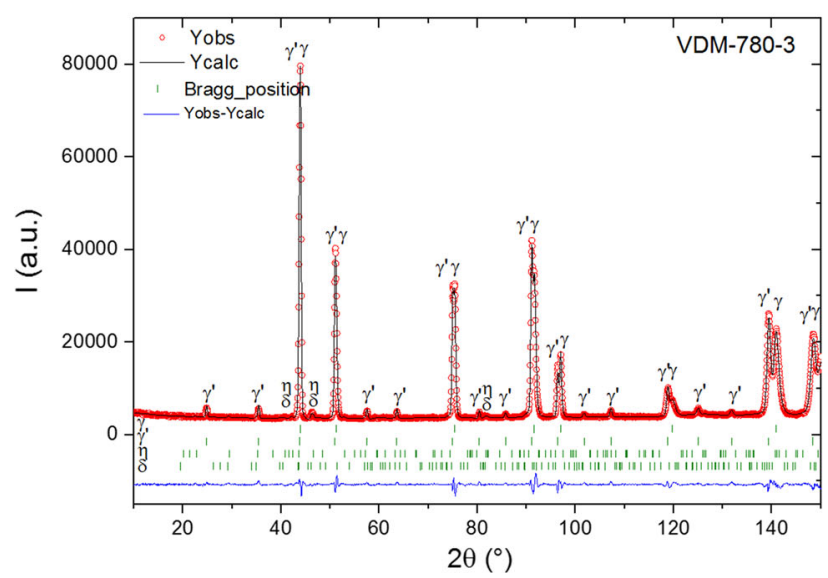

(c)

Fig. 6-High-resolution ND patterns and the results of the corresponding Rietveld refinement at RT of samples (a) VDM-780-1, (b) 2, and $(c) 3$. The observed data (red circles), calculated data (black line), and difference plots (blue line), together with the positions of the Bragg reflections, are depicted for all phases $\left(\gamma, \gamma^{\prime}, \eta\right.$, and $\delta$ green markers) (Color figure online). 
Table II. Lattice Parameters of the $\gamma$ and $\gamma^{\prime}$ Phases Obtained from Rietveld Refinement of the ND Patterns of the Three Samples and Weight Fractions (Percent) of Those Phases and the High-Temperature Phase

\begin{tabular}{|c|c|c|c|c|}
\hline & \multicolumn{3}{|c|}{ ND_Lattice Parameters $(\AA)$ and Weight Fractions of Participating Phases (Weight Percent) } & \multirow[b]{2}{*}{$\begin{array}{l}\text { Misfit } \\
\gamma-\gamma^{\prime}(\operatorname{Pct})\end{array}$} \\
\hline & $\begin{array}{l}\gamma \text {-Cubic } \\
(F m-3 m)\end{array}$ & $\gamma^{\prime}$-Cubic $(P m-3 m)$ & High-Temperature Phase $\eta(P 63 / m m c)$ or $\delta(P m m n)$ & \\
\hline VDM 780-1 & $a=3.5912(96.7 \mathrm{pct})$ & - & $\begin{array}{l}\eta: a=b=5.124, c=8.363 \\
\delta: a=5.158, b=4.181, c=4.442(3.3 \mathrm{pct})\end{array}$ & - \\
\hline VDM 780-2 & $a=3.58519(81.9 \mathrm{pct})$ & $a=3.60253(15.7 \mathrm{pct})$ & $\begin{array}{l}\eta: a=b=5.131, c=8.346 \\
\delta: a=5.164, b=4.134, c=4.334(2.4 \text { pct })\end{array}$ & 0.482 \\
\hline VDM 780-3 & $a=3.58094(60.5 \mathrm{pct})$ & $a=3.59824(35.0 \mathrm{pct})$ & $\begin{array}{l}\eta: a=b=5.122, c=8.343 \\
\delta: a=5.154, b=4.186, c=4.560(4.5 \mathrm{pct})\end{array}$ & 0.485 \\
\hline
\end{tabular}

$\eta$ phase (b), and both $\delta$ and $\eta$ high-temperature phases (c). It can be seen that, due to the very small amount of the high-temperature phase and the strong overlap of both hypothetical high-temperature phases, all three different refinements are quite similar (approximately the same $R$ values when taking into account the errors).

Because it is not easy to discern between $\delta$ and $\eta$ high-temperature phases from the XRD and ND studies, the presence of both phases is assumed for the Rietveld refinement and the comparison of the three different samples is shown in Figure 6. The red open circles show measured data, the black line the calculated data obtained from Rietveld refinement, and the lower blue line the difference between both data sets. The graphs also show the Bragg peak positions of the $\gamma$ matrix, $\gamma^{\prime}$-hardening phase, and the $\eta$ and $\delta$ high-temperature phases (green markers from top to bottom). The lattice parameters of all the phases and weight fractions (weight percent) of each phase obtained from the Rietveld refinement of the ND patterns of the three samples are summarized in Table II.

It is observed that lattice parameters depend slightly on the aging treatments, which give rise to the presence of different phases in the alloy with different particle sizes and volume fractions. From the Rietveld refinement, it was also possible to obtain an average crystallite size of $12 \pm 2 \mathrm{~nm}$ of the $\gamma^{\prime}$-hardening phase in sample VDM-780-2 using the Scherrer equation [1].

The good strength properties of the Ni-based alloys are highly dependent on the misfit between the $\gamma$-matrix and the $\gamma^{\prime}$-hardening phase, which is defined with Eq. [2] The misfit at RT of the different samples, obtained from the data of Table II, are 0.482 and 0.485 pct for samples VDM-780-2 and 3, respectively (note that the aging treatment of sample VDM-780-1 does not give rise to $\gamma^{\prime}$ precipitates).

In order to obtain the solvus temperature ( $\left.T_{\text {solvus }}\right)$ of the constituting phases, in situ high-temperature ND measurements were performed at HRPT (PSI) from RT up to $1080{ }^{\circ} \mathrm{C}$. Figure 7 shows the ND patterns $(2 \theta$ from 25 to $85 \mathrm{deg}$ ) of all three samples measured at different temperatures, and the main Bragg reflections are indexed. From the disappearance of the Bragg reflections of the $\gamma^{\prime}$ phase, best visible with the $\gamma^{\prime}(100)$ peak, which has no contribution of any other phase, it is found that the $T_{\text {solvus }}$ of the $\gamma^{\prime}$ phase is in the range of $995^{\circ} \mathrm{C}$ to $1000{ }^{\circ} \mathrm{C}$ for both samples VDM-780-2 and 3 (note that VDM-780-1 has no $\gamma^{\prime}$ phase). Similarly, the $T_{\text {solvus }}$ of the high-temperature phases is in the range of $1020^{\circ} \mathrm{C}$ to $1030{ }^{\circ} \mathrm{C}$, as can be concluded from the disappearance of the peaks at $2 \theta 56.7$ and $77.6 \mathrm{deg}$, respectively. The obtained value of the $T_{\text {solvus }}$ of the $\gamma^{\prime}$ phase, $995^{\circ} \mathrm{C}$ to $1000{ }^{\circ} \mathrm{C}$, is in good agreement with the ThermoCalc predictions obtained for the alloy $\mathrm{Ni}-18.7 \mathrm{Cr}-2.96-$ Mo-0.20Ti-2.0Al-5.4Nb-25.0Co (which is in the compositional range of Alloy 780). ${ }^{[22]}$ However, the $T_{\text {solvus }}$ of the high-temperature phase is a bit lower than the predicted one (over $\left.1100{ }^{\circ} \mathrm{C}\right) .{ }^{[22]}$ This can be ascribed to the increase with the temperature of the background in the ND patterns that do not allow seeing very small amounts of this phase in the patterns and the small difference in composition.

From the patterns, a slightly different behavior of some peaks assigned to the $\eta$ and $\delta$ high-temperature phases can be observed. This fact could suggest the existence of both high-temperature phases and a possible difference in the $T_{\text {solvus }}$ of them. In our future experiments, we will undertake measurements in order to discern the presence of the two different high-temperature phases, to stabilize one and to follow its evolution with the temperature.

From the Rietveld refinement of the in situ high-temperature ND patterns shown in Figure 7, the lattice parameters were obtained and the results are presented as a function of temperature in Figure 8 . The lattice constants of $\gamma$ and $\gamma^{\prime}$ phases slightly depend on the aging condition, while the misfit, which is similar for samples VDM-780-2 and 3, shows a slight decrease with increasing temperature, as it goes from 0.48 pct at RT to 0.45 and 0.44 pct at $950{ }^{\circ} \mathrm{C}$ for samples VDM-780-2 and 3, respectively (note that sample VDM-780-1 shows no $\gamma^{\prime}$ phase). This misfit decrease with temperature was observed previously in other superalloys with $\gamma / \gamma^{\prime}$ precipitate-strengthened microstructure ${ }^{[20,23]}$ and related to the dissolution of some of the $\gamma^{\prime}$-forming elements, such that the $\gamma$ phase can equilibrate to its most stable composition. ${ }^{[24]}$

Finally, in order to correlate the microstructure of the measured samples after the different aging treatments with their mechanical properties, the HV of the three different samples was measured and the results are summarized in Table III. It can be seen that HV values are in between 215 and 433 depending on the performed aging conditions. While sample VDM-780-1 shows the lowest $\mathrm{HV}$, corresponding to the material without 


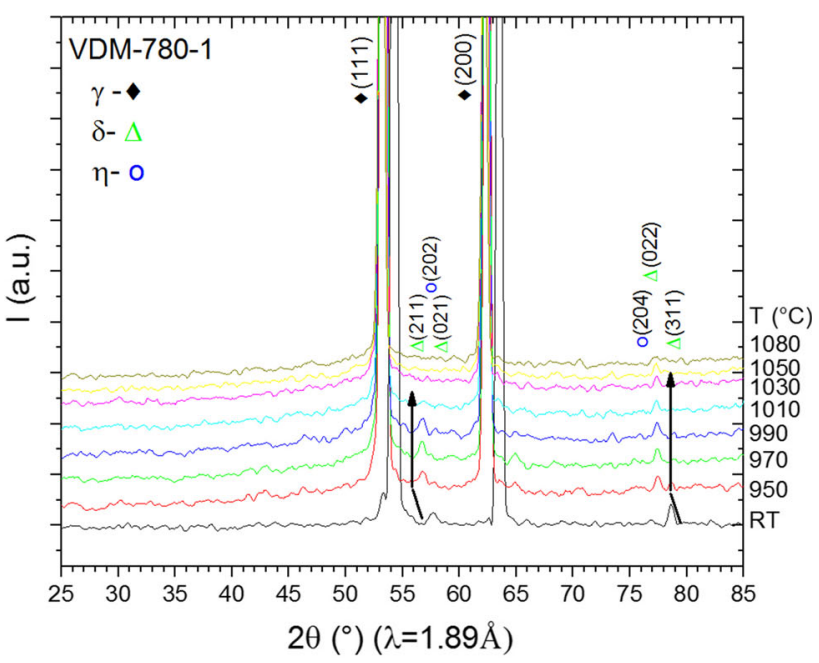

(a)

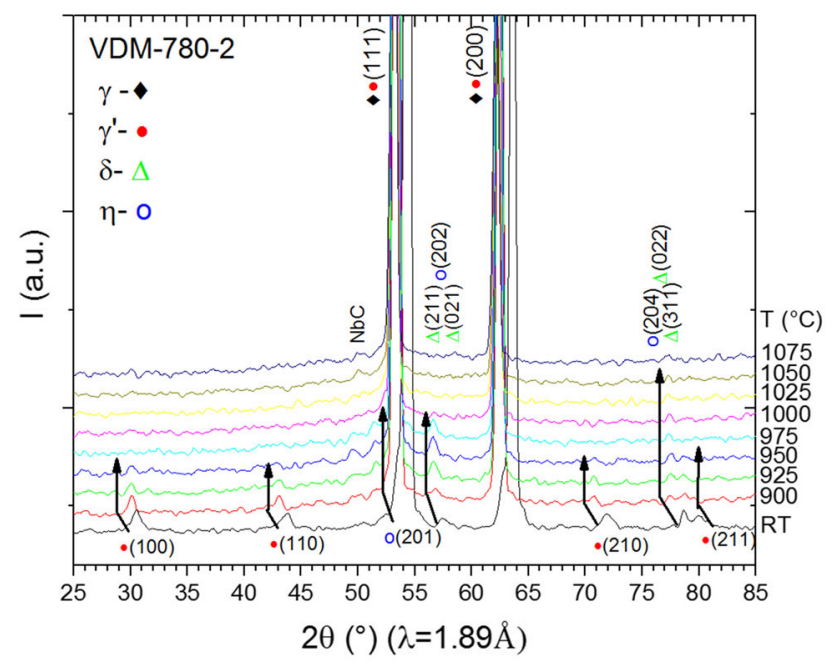

(b)

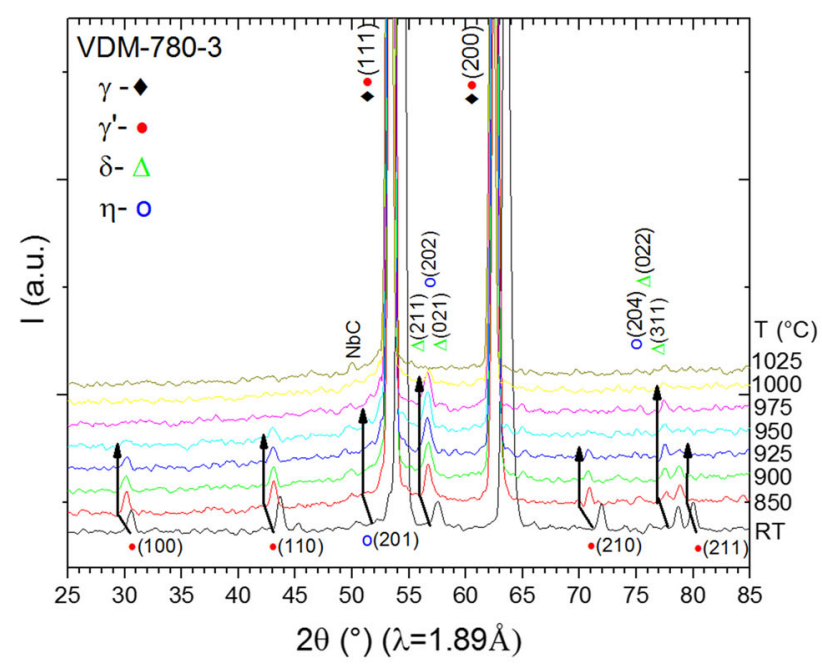

(c)

Fig. 7-In situ high-temperature ND patterns (from HRPT diffractometer at PSI) of samples (a) VDM-780-1, (b) 2, and (c) 3 performed at different selected temperatures for determination of the solvus temperatures.

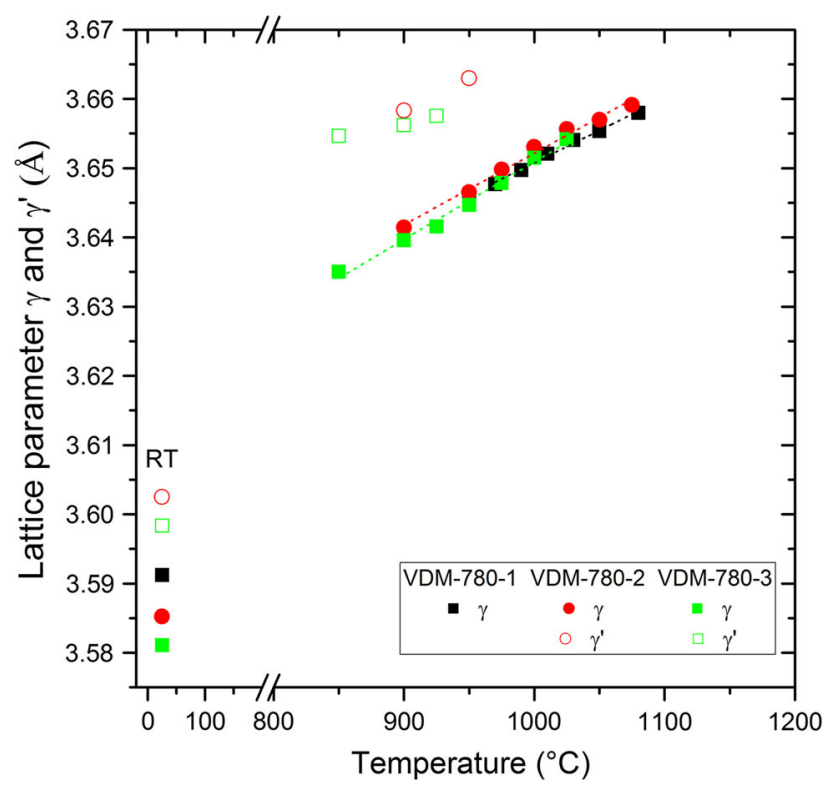

Fig. 8-Lattice parameters of the samples VDM-780-1, 2, and 3 as a function of the temperature, including RT measurements and measurements from $850{ }^{\circ} \mathrm{C}$ to $1100{ }^{\circ} \mathrm{C}$.

Table III. HV of the Three Different Samples Measured by Using Two Different Test Forces, HV3 and HV10

\begin{tabular}{lcc}
\hline Sample & HV3 & HV10 \\
\hline VDM-780-1 & $216(5)$ & $215(2)$ \\
VDM-780-2 & $432(5)$ & $429(9)$ \\
VDM-780-3 & $430(4)$ & $436(2)$ \\
\hline
\end{tabular}

$\gamma^{\prime}$-hardening phase, samples VDM-780-2 and 3 show similar HV values ( $431 \pm 9$ and $433 \pm 4$, respectively). For the explanation of the similar HV of the samples, both the amount of the $\gamma^{\prime}$-hardening phase and the crystallite size of these hardening precipitates have to be taken into account. As shown in Table II, sample VDM-780-3 presents $35.0 \mathrm{wt}$ pct of the $\gamma^{\prime}$-hardening phase, while sample 2 gives only 15.7 wt pct. This would give rise to higher HV of the sample VDM-780-3 if they had similar microstructure, but from Rietveld refinement and SEM analysis, we know that the average crystallite size of the $\gamma^{\prime}$-hardening phase in sample VDM-780-2 is in the nanometer region $(12 \pm 2 \mathrm{~nm})$ while the precipitates in sample VDM-780-3 are much larger (up to a few hundred nanometers (refer to the SEM images of Figure 1)). Thus, in sample VDM-780-2, the lower amount of $\gamma^{\prime}$-hardening phase is compensated by a reduction of the particle size, which gives rise to similar values of HV as in sample VDM-780-3 (with higher amount but larger precipitate size).

\section{SUMMARY AND CONCLUSIONS}

This article summarizes, for the first time, the morphology and the structural characterization of the new alloy VDM-780 Premium at RT and after three different aging treatments performed in order to form diverse 
microstructures. The structural characterization by means of neutron and XRD includes phase identification, determination of the lattice constants, and weight fractions of constituting phases by Rietveld refinements; nevertheless, the exact crystal structure of the high-temperature phase or the issue of the presence of two different high-temperature phases still remains open. All these parameters are correlated to the morphology observed by SEM. The solvus temperatures of the different observed phases, as well as the evolution of the lattice parameters with the temperature, were determined by in situ high-temperature ND. Finally, the HV values of the three samples are determined and the results are correlated with the amount and particle size of the $\gamma^{\prime}$-hardening phase of each sample.

\section{ACKNOWLEDGMENTS}

Financial support of this work via BMBF Project No. $05 \mathrm{~K} 16 \mathrm{WO} 2$ is kindly acknowledged. This work is based on experiments performed at the Heinz Maier-Leibnitz Zentrum (Garching, Germany) and at the Swiss spallation neutron source SINQ, Paul Scherrer Institute (PSI (Villigen, Switzerland)). The authors thank colleagues of both institutions, including the sample environment groups.

\section{OPEN ACCESS}

This article is distributed under the terms of the Creative Commons Attribution 4.0 International License (http://creativecommons.org/licenses/by/4.0/), which permits unrestricted use, distribution, and reproduction in any medium, provided you give appropriate credit to the original author(s) and the source, provide a link to the Creative Commons license, and indicate if changes were made.

\section{REFERENCES}

1. T.M. Pollock and S. Tin: J. Propul. Power., 2006, vol. 22, pp. 361-74.
2. D. Furrer and H. Fecht: J. Miner. Metall. Mater. Soc., 1999, vol. 51, pp. 14-17.

3. N. Wagner, M. Hofmann, S. Van Petegem, C. Krempaszky, M. Hoelzel, and M. Stockinger: Mater. Sci. Eng. A-Struct., 2016, vol. 662, pp. 303-07.

4. D. Mukherji, P. Del Genovese, P. Strunz, R. Gilles, A. Wiedenmann, and J. Rösler: J. Phys., 2008, vol. 20, pp. 104220-1-104220-9.

5. R. Gilles, D. Mukherji, H. Eckerlebe, L. Karge, P. Staron, P. Strunz, and T. Lippmann: J. Alloys Compd., 2014, vol. 612, pp. $90-97$.

6. C. Slama and M. Abdellaoui: J. Alloy Compd., 2000, vol. 306, pp. 277-84.

7. P. Del Genovese, D. Strunz, D. Mukherji, R. Gilles, and J. Rösler: Metall. Mater. Trans. A, 2005, vol. 36A, pp. 3439-50.

8. M. Fisk, J. Andersson, R. du Rietz, S. Haas, and S. Hall: Mater. Sci. Eng. A-Struct., 2014, vol. 612, pp. 202-07.

9. S. Antonov, M. Detrois, R.C. Helmink, and S. Tin: J. Phys., 2015, vol. 626 , pp. $76-86$.

10. T. Fedorova, J. Rösler, J. Kloewer, and B. Gehrmann: Matec. Web Conf., 2014, vol. 14, pp. 01003-1-01003-6.

11. M. Wang, J. Du, Q. Deng, Z. Tian, and J. Zhu: J. Alloy Compd., 2017, vol. 701, pp. 635-44.

12. T. Fedorova, J. Rösler, B. Gehrmann, and J. Kloewer: 8th Int. Symp. on Superalloy 718 and Derivates, E. Ott, A. Banik, J. Andersson, I. Dempster, T. Gabb, J. Groh, K. Heck, R. Helmink, X. Liu, and A. Wusatowska-Sarnek, eds., TMS, Warrendale, PA, 2014, pp. 587-99.

13. R. Gilles, B. Krimmer, H. Boysen, and H. Fuess: Appl. Phys. A, 2002, vol. 74, pp. 148-50.

14. M. Hoelzel, A. Senyshyn, N. Juenke, H. Boysen, W. Schmahl, and H. Fuess: Nucl. Instrum. A, 2012, vol. 667, pp. 32-37.

15. G. Fischer, M. Frey, M. Koch, M. Könnecke, V. Pomjakushin, J. Schefer, R. Thut, N. Schlumpf, R. Bürge, U. Greuter, S. Bondt, and E. Berruyer: Phys. B, 2000, vols. 276-278, pp. 146-47.

16. M. Rietveld: J. Appl. Crystallogr., 1969, vol. 2, pp. 65-71.

17. T. Degen, M. Sadki, E. Bron, U. König, and G. Nénert: Powder Diffr., 2014, vol. 29 (S2), pp. 13-18.

18. J. Rodríguez-Carvajal: Phys. B Condens. Matter., 1993, vol. 192, pp. 55-69.

19. H. Chung and D.K. Smith: Industrial Applications of X-ray Diffraction, Marcel Dekker Inc, New York, NY, 2000.

20. P. Strunz, M. Petrenec, V. Davydov, J. Polák, and P. Beran: $A d v$. Mater. Sci. Eng., 2013, vol. 2013, pp. 408347-1-408347-7.

21. S. Antonov, J. Huo, Q. Feng, D. Isheim, D.N. Seidman, R.C. Helmink, E. Sun, and S. Tin: Mater. Sci. Eng. A, 2017, vol. 687, pp. $232-40$.

22. T. Fedorova: Entwicklung einer neuen Nickelbasis-Superlegierung auf Basis von Alloy 718, Gulliver Verlag, Göttingen, 2013.

23. J. Coakley, E.A. Lass, D. Ma, M. Frost, H.J. Stone, D.N. Seidman, and D.C. Dunand: Acta Mater., 2017, vol. 136, pp. $118-25$.

24. N. Saunders, Z. Guo, X. Li, A.P. Miodownik, and J.P. Schille: Superalloys 2004, K.A. Green, T.M. Pollock, and H. Harada, eds., TMS, Warrendale, PA, 2004, pp. 849-58. 